\title{
Legislación y conceptos aplicables a las áreas naturales protegidas en el Perú
}

\section{Legislation and applicable concepts to protected natural areas in Peru}

\section{PEDRO SOLANO*}

Resumen: En el Perú existen setenta y ocho áreas protegidas de nivel nacional, que en su conjunto cubren más de veinte y dos millones de hectáreas que equivalen casi al diecisiete por ciento del territorio nacional. El presente artículo, tras abordar los alcances, objetivos, tipos, categorías y niveles de las áreas naturales protegidas, pasa revista a los más trascendentes aspectos que las envuelven, tales como los requerimientos para su establecimiento, modificación y derogación; las actividades permitidas y prohibidas dentro de ellas; su gestión institucional; entre otros. Finalmente arriba a unas concisas reflexiones sobre los retos legales e institucionales que el Sistema Nacional de Áreas Naturales Protegidas por el Estado (SINANPE) debería afrontar.

Palabras clave: áreas naturales protegidas - Sistema Nacional de Áreas Naturales Protegidas por el Estado - actividades permitidas y prohibidas gestión institucional - normas y penalidades

Summary: There are 78 protected areas in Peru covering 22 million hectares corresponding almost 17 percent of national territory. This article reviews essential aspects of protected natural areas studying scopes, purposes, types, categories and levels such as: requirements for setting, amendment and repeal; activities allowed and forbidden within them; institutional management, among others. Finally, this work concludes with some brief thoughts on legal and institutional challenges of the Sistema Nacional de Áreas Naturales Protegidas por el Estado (SINANPE) (National System of State Protected Natural Areas).

Key words: protected natural areas - National System of State Protected Natural Areas - allowed and forbidden activities - institutional management rules and penalties

* Pedro Solano es director ejecutivo de la Sociedad Peruana de Derecho Ambiental (SPDA), institución a la que pertenece desde 1988. Actualmente es también miembro del Consejo Directivo del Servicio Nacional de Áreas Naturales Protegidas por el Estado (SERNANP). Correo electrónico: psolano@ spda.org.pe 
CONTENIDO: I. INTRODUCCIÓN.- II. DEFINICIÓN Y OBJETIVOS DE LAS ÁREAS NATURALES PROTEGIDAS.- III. TIPOS DE ÁREAS PROTEGIDAS, CATEGORÍAS Y NIVELES.- IV. ESTABLECIMIENTO, MODIFICACIÓN Y DEROGACIÓN DE ÁREAS NATURALES PROTEGIDAS.- $V$. ACTIVIDADES PERMITIDAS Y PROHIBIDAS DENTRO DE LAS ÁREAS NATURALES PROTEGIDAS.- VI. GESTIÓN INSTITUCIONAL DE LAS ÁREAS NATURALES PROTEGIDAS. - VII. IMPLEMENTACIÓN DE LAS NORMAS Y PENALIDADES.- VIII. DERECHOS DE PROPIEDAD Y OTROS DERECHOS PREEXISTENTES AL ESTABLECIMIENTO DEL ÁREA NATURAL PROTEGIDA.- IX. CO-MANEJO O MANEJO DELEGADO DE ÁREAS PROTEGIDAS POR INSTITUCIONES DE DERECHO PRIVADO.- X. RETOS HACIA EL FUTURO.

\section{INTRODUCCIÓN}

El Perú es un país con un territorio de ciento veintiocho millones de hectáreas y una población aproximada de veintinueve millones de personas. El territorio peruano comprende ochenta y tres zonas de vida y una gran diversidad biológica, lo que lo ha calificado como uno de los países megadiversos del planeta. La ubicación geográfica del Perú, entre los Andes amazónicos sudamericanos y la costa del océano Pacífico con presencia constante de la corriente de Humboldt, ha determinado que el país tenga una marcada división entre una costa semiárida con fuertes corrientes de aguas frías (diez por ciento del territorio terrestre), una zona andina montañosa con alturas de hasta los seis mil ochocientos metros sobre el nivel del mar (treinta por ciento aproximadamente) y una exuberante selva amazónica que cubre cerca al sesenta por ciento del territorio peruano. La población peruana, sin embargo, está altamente concentrada en la costa, donde vive el setenta por ciento de la población. Solo en la ciudad de Lima viven más de ocho millones de peruanos, casi la tercera parte de la población nacional.

El primer Parque Nacional peruano fue establecido en $1961^{1}$ mediante ley del Congreso de la República. Desde esa fecha se han establecido setenta y ocho áreas protegidas de nivel nacional, quince de nivel regional o departamental y cincuenta y siete áreas de conservación privadas, que en su conjunto conforman el Sistema Nacional de Áreas Naturales Protegidas por el Estado (SINANPE) ${ }^{2}$. Las áreas naturales protegidas en su conjunto cubren más de veinte y dos millones de hectáreas que equivalen casi al diecisiete por ciento del territorio nacional. Durante la mayor parte de estos años el SINANPE fue administrado por oficinas de distinto nivel y denominación, todas ellas adscritas al Ministerio de Agricultura. En el año 2008 estas funciones fueron asignadas al

1 El Parque Nacional Cutervo.

2 EI SINANPE, de acuerdo con la Ley de Áreas Naturales Protegidas, solo está conformado por las áreas de nivel nacional. Las áreas regionales y privadas son denominadas «áreas complementarias al SINANPE». La legislación peruana no incluye áreas protegidas de nivel municipal, aunque existen distintos proyectos de ley orientados a sumar este nivel de áreas protegidas al Sistema. 
Servicio Nacional de Áreas Naturales Protegidas (SERNANP), que es un organismo técnico especializado bajo el portafolio del Ministerio del Ambiente ${ }^{3}$.

El SINANPE tiene su base legal principal en la Ley de Áreas Naturales Protegidas, aprobada por el Congreso de la República en julio de $1997^{4}$. Esta ley cuenta con varias regulaciones generales y específicas. Asimismo, existen otras normas ambientales que abordan temas de áreas naturales protegidas.

- Las normas relacionadas a áreas naturales protegidas de mayor importancia son las siguientes: la Ley de Creación del Fondo Nacional para la Áreas Naturales Protegidas por el Estado;

- el decreto ley 26154 de 1992;

- el mandato constitucional del artículo 68 de la Constitución Política del Perú de 1993;

- el reglamento de la ley que crea el Fondo Nacional para las Áreas Naturales Protegidas por el Estado, decreto supremo 043-94-AG de 1994;

- la Ley de Áreas Naturales Protegidas, ley 26834 de 1997;

- la Ley sobre la Conservación y Aprovechamiento Sostenible de la Diversidad Biológica, ley 26831 de 1997;

- el Plan Director de las Áreas Naturales Protegidas, decreto supremo 016-2009-MINAM de 2009;

- el reglamento de la Ley de Áreas Naturales Protegidas, decreto supremo 038-2001-AG de 2001;

- la Ley General del Ambiente, ley 28611 de 2005;

- la ley que crea el Ministerio del Ambiente y el Servicio Nacional de Areas Naturales Protegidas, decretos legislativos 1013 y 1039 de 2008;

- ley que establece medidas que garanticen el patrimonio de las áreas naturales protegidas, decreto legislativo 1079 de 2008;

- el Reglamento de Organización y Funciones del SERNANP, decreto supremo 006-2008-MINAM de 2008;

- las disposiciones para la elaboración de Planes Maestros, decreto supremo 008-2009-AG de 2009;

- el reglamento de Uso Turístico de las Áreas Naturales Protegidas, decreto supremo 018-2009-MINAM de 2009;

- el reglamento del Procedimiento Administrativo Sancionador por Afectación a la Áreas Naturales Protegidas, decreto supremo 019-2010-MINAM de 2010;

3 El Ministerio del Ambiente fue creado en mayo de 2008 mediante el decreto legislativo 1013. El SERNANP asumió plenamente sus funciones en relación con las áreas protegidas en enero de 2009.

4 Ley 26834. 
- la creación del Registro de Infractores por Afectación a las Áreas Naturales Protegidas de Nivel Nacional, resolución de Secretaría General 011-2011- SERNANP de 2011.

\section{DEFINICIÓN Y OBJETIVOS DE LAS ÁREAS} NATURALES PROTEGIDAS

La definición, de acuerdo con la Ley de Áreas Naturales Protegidas de 1997, dice a la letra que:

[...] las áreas naturales protegidas son los espacios continentales y/o marinos del territorio nacional, expresamente reconocidos y declarados como tales, incluyendo sus categorías y zonificaciones, para conservar la diversidad biológica y demás valores asociados de interés cultural, paisajístico y científico, así como por su contribución al desarrollo sostenible del país. Las áreas Naturales Protegidas constituyen patrimonio de la Nación. Su condición natural debe ser mantenida a perpetuidad pudiendo permitirse el uso regulado del área y el aprovechamiento de recursos, o determinarse la restricción de los usos directos 5 .

De acuerdo con la definición legal de área natural protegida contenida en el artículo 1 de la ley de 1997, el objetivo primario de cualquier área natural protegida es la conservación de la diversidad biológica. Como objetivos complementarios se mencionan los valores asociados de interés cultural, paisajístico y científico; así como la contribución de las áreas al desarrollo sostenible del país.

En una explicación mucho más sencilla puede decirse que las áreas protegidas son una especie de «seleccionado» del patrimonio natural de un país. Se eligen las que poseen la mayor calidad, reúnen las mejores condiciones y representan mejor ese patrimonio. La idea es que esas áreas, a la vez de proteger el patrimonio de todos, generen oportunidades de gestión vinculadas a la puesta en valor de los espacios mediante cualquiera de las estrategias de conservación disponibles, entre ellas la protección, mantenimiento, uso sostenible y restauración.

\section{TIPOS DE ÁREAS PROTEGIDAS, CATEGORÍAS Y NIVELES}

No todas las áreas protegidas son iguales. Así como en un seleccionado deportivo no todos los jugadores cumplen la misma función, aunque el objetivo último de todos ellos sea el mismo; las áreas protegidas se identifican y clasifican por sus objetivos de manejo. Estos, normalmente, están asociados a las estrategias de conservación preponderantes que justificaron la elección de dicho espacio como área protegida. 
En una primera aproximación, la ley de 1997 establece que:

[...] las Áreas Naturales Protegidas contemplan una gradualidad de opciones que incluyen:

a. Áreas de uso indirecto. Sonaquellas que permiten lainvestigación científica no manipulativa, la recreación y el turismo, en zonas apropiadamente designadas y manejadas para ello. En estas áreas no se permite la extracción de recursos naturales, así como modificaciones y transformaciones del ambiente natural. Son áreas de uso indirecto los Parques Nacionales, Santuarios Nacionales y los Santuarios Históricos.

b. Áreas de uso directo. Son aquellas que permiten el aprovechamiento o extracción de recursos, prioritariamente por las poblaciones locales, en aquellas zonas y lugares y para aquellos recursos, definidos por el plan de manejo del área. Otros usos y actividades que se desarrollen deberán ser compatibles con los objetivos del área.

Son áreas de uso directo las Reservas Nacionales, Reservas Paisajísticas, Refugios de Vida Silvestre, Reservas Comunales, Bosques de Protección, Cotos de Caza y Áreas de Conservación Regionales ${ }^{6}$.

Los diferentes nombres que reciben las áreas protegidas como «parque», «santuarios» o «reservas» es lo que se conoce como categorías. Las categorías de áreas protegidas son las que indican el modelo de gestión preponderante de la misma, de acuerdo a sus objetivos de conservación. En el Perú existen nueve categorías para las áreas naturales protegidas de nivel nacional. Estas categorías, definidas en la propia ley de 1997, son las siguientes.

a. Parques Nacionales: áreas que constituyen muestras representativas de la diversidad natural del país y de sus grandes unidades ecológicas. En ellos se protege con carácter intangible la integridad ecológica de uno o más ecosistemas, las asociaciones de la flora y fauna silvestre y los procesos sucesionales y evolutivos, así como otras características, paisajísticas y culturales que resulten asociadas $^{7}$.

A la fecha existen trece parques nacionales establecidos sobre una superficie de 8170 747,54 hectáreas.

6 Artículo 21 de la ley 26834, Ley de Áreas Naturales Protegidas. Las áreas de conservación regionales son un nivel departamental de áreas protegidas a cargo de los gobiernos regionales.

7 Artículo 22 de la ley 26834, Ley de Áreas Naturales Protegidas.

LEGISLACIÓN

Y CONCEPTOS

APLICABLES

A LAS ÁREAS

NATURALES

PROTEGIDAS EN

EL PERÚ

LEGISLATION

AND APPLICABLE

CONCEPTS TO

PROTECTED

NATURAL AREAS

IN PERU 
b. Santuarios Nacionales: áreas donde se protege con carácter intangible el hábitat de una especie o una comunidad de la flora y fauna, así como las formaciones naturales de interés científico y paisajístico ${ }^{8}$.

A la fecha existen nueve santuarios nacionales, sobre una superficie de 317 366,47 hectáreas.

c. Santuarios Históricos: áreas que protegen con carácter de intangible espacios que contienen valores naturales relevantes y constituyen el entorno de sitios de especial significación nacional, por contener muestras del patrimonio monumental y arqueológico o por ser lugares donde se desarrollaron hechos sobresalientes de la historia del país.

A la fecha el Perú cuenta con cuatro santuarios históricos, sobre una superficie de 41 279,38 hectáreas.

d. Reservas Paisajísticas: áreas donde se protege ambientes cuya integridad geográfica muestra una armoniosa relación entre el hombre y la naturaleza, albergando importantes valores naturales, estéticos y culturales ${ }^{10}$.

A la fecha se han establecido dos reservas paisajísticas, sobre una superficie de 711818,48 hectáreas.

e. Refugios de Vida Silvestre: áreas que requieren intervención activa con fines de manejo, para garantizar el mantenimiento de los hábitats, así como para satisfacer las necesidades particulares de determinadas especies, como sitios de reproducción y otros sitios críticos para recuperar o mantener las poblaciones de tales especies ${ }^{11}$.

Ya se han establecido a la fecha tres refugios de vida silvestre, sobre una superficie de 20775,11 hectáreas.

f. Reservas Nacionales: áreas destinadas a la conservación de la diversidad biológica y la utilización sostenible de los recursos de flora y fauna silvestre, acuática o terrestre. En ellas se permite el aprovechamiento comercial de los recursos naturales bajo planes de manejo, aprobados, supervisados y controlados por la autoridad nacional competente ${ }^{12}$. 
A la fecha se han establecido quince reservas nacionales, sobre una superficie de 4652851,63 hectáreas.

g. Reservas Comunales: áreas destinadas a la conservación de la flora y fauna silvestre, en beneficio de las poblaciones rurales vecinas. El uso y comercialización de recursos se hará bajo planes de manejo, aprobados y supervisados por la autoridad y conducidos por los mismos beneficiarios. Pueden ser establecidas sobre suelos de capacidad de uso mayor agrícola, pecuario, forestal o de protección y sobre humedales ${ }^{13}$.

A la fecha se han establecido diez reservas comunales, sobre una superficie de 2166 588,44 hectáreas.

h. Bosques de Protección: áreas que se establecen con el objeto de garantizar la protección de las cuencas altas o colectoras, las riberas de los ríos y de otros cursos de agua y en general, para proteger contra la erosión a las tierras frágiles que así lo requieran. En ellos se permite el uso de recursos y el desarrollo de aquellas actividades que no pongan en riesgo la cobertura vegetal del área ${ }^{14}$.

En el Perú se han establecido seis bosques de protección, sobre una superficie de 389 986,99 hectáreas.

i. Cotos de Caza: áreas destinadas al aprovechamiento de la fauna silvestre a través de la práctica regulada de la caza deportiva ${ }^{15}$.

Caen dentro de una Categoría VI de la Unión Internacional para la Conservación de la Naturaleza (UICN) y a la fecha se han establecido dos Cotos de Caza, sobre una superficie de 124 735,00 hectáreas.

Adicionalmente, el Sistema peruano contempla un estatus transitorio denominado zona reservada, que es un espacio seleccionado para la conservación de la diversidad biológica y que requiere estudios complementarios para definir la extensión y categoría que le correspondería como área protegida. En la práctica, la mayoría de áreas protegidas establecidas en los últimos quince años pasaron por un período previo como zonas reservadas. Los procesos de categorización han definido casi siempre que las zonas reservadas se conviertan en una o más áreas naturales protegidas del Sistema Nacional, aunque nada impide que la categorización determine también un área de nivel regional. En algunos casos la categorización ha significado también la liberación de áreas que no forman parte de las áreas protegidas que finalmente se definen. A la fecha existen trece zonas reservadas 
esperando por su categorización definitiva, que cubren una superficie total de 2932 715,23 hectáreas.

El Sistema se complementa con dos niveles, uno subnacional y el segundo en el ámbito privado. A las primeras se les denomina áreas de conservación regionales y las segundas son las áreas de conservación privadas. Las áreas de conservación regionales se establecen sobre áreas que teniendo importancia para la conservación de la diversidad biológica no califican para ser declaradas como áreas de nivel nacional, es decir son áreas en las que el interés para su conservación corresponde a un nivel departamental o regional. A la fecha existen quince áreas de conservación regionales establecidas, sobre una superficie de 2405 558,82 hectáreas. Varios gobiernos regionales, adicionalmente, han establecido, mediante ordenanza, sus propios Sistemas Regionales de Conservación para gestionar de manera organizada las estrategias de conservación de sitios en el ámbito regional.

En el caso de los gobiernos locales o municipales, la legislación no ha previsto un nivel de áreas protegidas municipales, lo que ha motivado una controversia en el país, dado que existe el deseo de muchos municipios por establecer y gestionar áreas protegidas en su jurisdicción. Deseo que han materializado estableciendo áreas que no encajan de una manera clara en la legislación nacional. Como resultado, existen más de setenta áreas de conservación municipales establecidas por los propios municipios, áreas cuya legalidad podría ser cuestionada. El grado limitado en que se ha incorporado este nivel de áreas dentro del Sistema Nacional de Áreas Naturales Protegidas ha tenido principalmente que ver con el temor del sector minero de que este instrumento sea utilizado políticamente por alcaldes para imponer restricciones de uso en áreas de interés minero.

En el año 2007 un decreto supremo precisó que las iniciativas municipales de conservación bajo cualquier denominación no corresponden al ámbito de las áreas naturales protegidas y, por lo tanto, no les resultan aplicables las normas sobre la materia. Esta norma, sin embargo, no ha sido impedimento para que los municipios, en el marco de otras normas, sigan estableciendo o protegiendo espacios naturales de sus localidades; aunque queda poco claro cuál es la consecuencia legal de esas normas o declaraciones. Existen algunos proyectos de ley orientados a resolver este tema, pero lamentablemente, no constituyen aún una prioridad política y la incertidumbre prevalece.

Por su parte, las áreas de conservación privadas son áreas de propiedad individual o colectiva con valores para la conservación de la diversidad biológica y cuyo propietario, voluntariamente, decide imponerle cargas o condiciones de uso para conservar dichos predios y solicita al gobierno su reconocimiento como tales. A la fecha existen cincuenta y siete áreas de conservación privadas formalmente reconocidas, sobre una 
superficie total de 253 461,68 hectáreas. Entre ellas, hay tanto predios de propietarios individuales como predios bajo propiedad colectiva.

El Estado otorga una aprobación formal a las áreas de conservación privadas a través de la norma de más alto nivel ministerial que es la resolución ministerial. La palabra empleada para esta aprobación no es «establecimiento» o «declaración», sino «reconocimiento», ya que se entiende que las áreas de conservación privadas son esfuerzos voluntarios de los propietarios, reconocidos por el gobierno.

Las zonas de amortiguamiento existen como concepto en el Perú al menos desde la década de 1980, a partir de los planes maestros de esos años. Es justamente en los procesos de planificación de las áreas naturales protegidas que se advirtió la necesidad de mirar también hacia afuera de ellas, a su entorno inmediato, para que las actividades que se realicen ahí no impacten negativamente sobre el área protegida, pero sobre todo para que estas no se aíslen de su entorno, sino que pueda garantizarse una continuidad más allá de los límites del área, con una gradación de actividades que de una manera más natural garanticen los objetos de conservación del área protegida. A nivel legal, sin embargo, las zonas de amortiguamiento surgieron recién con la Ley de Áreas Naturales Protegidas en 1997.

De acuerdo a esta ley, «son zonas de amortiguamiento aquellas zonas adyacentes a las áreas naturales protegidas del Sistema, que por su naturaleza y ubicación requieren un tratamiento especial para garantizar la conservación del área protegida». La norma agrega que «el Plan Maestro de cada área definirá la extensión que corresponda a su zona de amortiguamiento» y la única pista respecto a las restricciones de uso es que «las actividades que se realicen en las zonas de amortiguamiento no deben poner en riesgo el cumplimiento de los fines del área natural protegida» ${ }^{16}$.

Si bien las zonas de amortiguamiento no son parte del área natural protegida, la idea detrás de estas, más que un tema de jurisdicción, es la promoción de actividades. Es decir, la autoridad del área protegida ejercerá un rol promotor y de buen vecino, procurando alentar las actividades compatibles o sugeridas por el reglamento y desalentar, mediante el convencimiento, las actividades no compatibles.

De acuerdo con el reglamento ${ }^{17}$, solo hay tres competencias directas o administrativas asignadas a la autoridad del área protegida sobre su zona de amortiguamiento: la primera es delimitarla, la segunda es dar opinión previa favorable para la autorización de actividades forestales o cualquiera que requiera un estudio de impacto ambiental (EIA) o programa de adecuación y manejo ambiental (PAMA), y la última es

\section{LEGISLACIÓN Y CONCEPTOS APLICABLES A LAS ÁREAS NATURALES PROTEGIDAS EN EL PERÚ}

LEGISLATION AND APPLICABLE CONCEPTS TO PROTECTED NATURAL AREAS IN PERU 
supervisar y monitorear las actividades que se realicen en la zona de amortiguamiento $^{18}$.

\section{Cuadro 1. Principales hitos de la evolución legislativa de las áreas naturales protegidas y de sus categorías en el Perú}

1941 Perú suscribe convención de Washington para la protección de las bellezas escénicas de América.

1961 Se establece primer Parque Nacional, en Cutervo, por ley del Congreso.

1963 Ley del Servicio Forestal y de Caza, incluye categoría de Parque Nacional.

1967 Ley de Promoción y Desarrollo Agropecuario y su reglamento, incorpora categorías de reservas nacionales y santuarios nacionales.

1975 Ley Forestal y de Fauna Silvestre, y su Reglamento de Unidades de Conservación, 1977; incorpora santuarios históricos y define Sistema Nacional de Unidades de Conservación (SINUC), conformado por Parques, Reservas y Santuarios Nacionales; más la nueva categoría de Santuarios Históricos.

1990 - Se conforma el Sistema Nacional de Áreas Naturales Protegidas por el Estado (SINANPE), sobre la base del SINUC más cuatro categorías adicionales: bosques nacionales, bosques de protección, cotos de caza, reservas comunales.

- Código del Medio Ambiente, incluye capítulo sobre las áreas protegidas.

1992 Perú suscribe convenio de diversidad biológica.

1996 Los bosques nacionales son excluidos del SINANPE, en el entendido de que son áreas para la producción sostenible de madera.

1997 - Ley sobre la conservación y aprovechamiento sostenible de la diversidad biológica.

- Ley de Áreas Naturales Protegidas, incorpora los refugios de vida silvestre y las reservas paisajísticas al SINANPE y redefine todas las categorías.

1999 Primer Plan Director de las áreas naturales protegidas es aprobado.

2001 Reglamento de la Ley de Áreas Naturales Protegidas.

2005 Ley General del Ambiente. Deroga el Código del Medio Ambiente.

2008 Ley que establece medidas para garantizar el patrimonio de las áreas naturales protegidas. 


\section{ESTABLECIMIENTO, MODIFICACIÓN Y DEROGACIÓN DE ÁREAS NATURALES PROTEGIDAS}

Las áreas naturales protegidas se establecen por decreto supremo y solo pueden modificarse o derogarse por ley del Congreso de la República. Las zonas reservadas y las áreas de conservación privadas se establecen o reconocen por resolución ministerial del Ministerio del Ambiente. Las zonas de amortiguamiento usualmente se definen en el Plan Maestro de cada área natural protegida (ANP), documento que se aprueba por resolución presidencial del SERNANP.

Usualmente, la ruta en el diseño y aprobación de las áreas protegidas peruanas ha sido la siguiente: grupos de la sociedad civil desarrollan estudios sobre áreas priorizadas para la conservación de la diversidad biológica de acuerdo al Plan Director del Sistema ${ }^{19}$. Luego llevan su propuesta a la autoridad nacional de áreas naturales protegidas, quien evalúa el expediente y solicita el desarrollo de talleres de consulta a nivel local y nacional. Con esa información se perfila el establecimiento de una Zona Reservada, a ser aprobada por resolución ministerial. La norma que establece la Zona Reservada nombra una Comisión de Categorización, integrada por representantes de distintos grupos de interés a nivel nacional, tanto públicos como privados; y presidida por un representante del SERNANP. Luego la comisión elabora un expediente técnico de categorización, que nuevamente incluye talleres de socialización de la propuesta y entrega su propuesta de categorización, la cual puede definir una o varias áreas protegidas y la ampliación o reducción de extensión a ser finalmente categorizada. Es entonces que la autoridad de ANP eleva el expediente al Ministerio del Ambiente quien luego de revisarlo proyecta el decreto supremo para ser evaluado y aprobado en el Consejo de Ministros. Finalmente se aprueba el decreto supremo, refrendado por el ministro del Ambiente y con la aprobación del Consejo de Ministros y la firma del presidente de la República. En el caso de las áreas de conservación regionales, esta ruta varía. Es el propio gobierno regional quien remite el expediente técnico a la autoridad nacional y luego sigue el proceso de la manera explicada.

Como ya se mencionó, de acuerdo con la Ley de Áreas Naturales Protegidas ${ }^{20}$, la reducción física o modificación legal de las áreas de nivel nacional solo puede ser aprobada por ley del Congreso de la República. La reducción física se refiere a recortar un área natural protegida y la modificación legal se refiere a, por ejemplo, cambiar su categoría, asignarle una naturaleza jurídica diferente o inclusive eliminar el área protegida como tal. Hasta la fecha no ha habido ningún caso de reducción física o

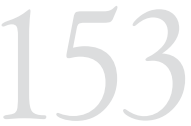

LEGISLACIÓN Y CONCEPTOS APLICABLES A LAS ÁREAS NATURALES PROTEGIDAS EN EL PERÚ

LEGISLATION AND APPLICABLE CONCEPTS TO PROTECTED NATURAL AREAS IN PERU 
modificación legal de áreas protegidas, aunque sí existió un caso en que se discutió esa posibilidad ${ }^{21}$.

Este esquema de establecer todas las áreas por la norma de mayor nivel del Gobierno Central y modificarlas por la norma más alta del Congreso de la República ha tenido efectos muy positivos en cuanto a la seguridad jurídica de las áreas, frente a políticas cambiantes de los gobiernos de turno. Sin embargo, también es cierto que ha dificultado algunos aspectos para una mejor operatividad del Sistema y sobre todo para la gobernanza del mismo.

Por un lado, las modificaciones legales que las áreas protegidas requieren son muchas veces cuestiones técnicas donde un área fue originalmente mal categorizada o los objetivos de manejo mal definidos. Y el requisito de la ley del Congreso para estos casos resulta siendo una valla muy alta de superar. Como consecuencia, muchas áreas arrastran por años problemas derivados de una mala definición que a la autoridad nacional le cuesta mucho corregir formalmente. Otro punto a tomar en cuenta es que si bien existen muchas normas sobre los contenidos técnicos para establecer las áreas, no existen los mismos requisitos para modificarlas o derogarlas, por lo cual este tipo de decisiones están más condicionadas a justificaciones políticas que técnicas, lo cual pone en peligro la integridad del Sistema.

En el caso de las áreas de conservación regionales, existe un vacío legal ya que no se ha establecido cómo es que pueden modificarse o derogarse estas áreas. Ante el vacío, la presunción es que se requeriría una norma de igual rango que aquella por la cual se estableció el área, es decir, un decreto supremo con voto aprobatorio del Consejo de Ministros. En el caso de las áreas de conservación privadas, estas pueden modificarse o extinguirse por cumplimiento del plazo (mínimo diez años), o por acuerdo entre el propietario y la autoridad nacional de áreas naturales protegidas.

\section{ACTIVIDADES PERMITIDAS Y PROHIBIDAS DENTRO DE LAS ÁREAS NATURALES PROTEGIDAS} El régimen de actividades permitidas en un área natural protegida depende de su categoría, norma de creación y, fundamentalmente, de lo que establezca su Plan Maestro. En este sentido, tanto las actividades consuntivas, como no consuntivas deben estar enmarcadas dentro de lo que el Plan Maestro del área haya establecido para el cumplimiento de los objetivos de la misma. Estas actividades son autorizadas por el jefe del Área o el propio SERNANP, salvo en aquellos casos en que la

21 El caso de la posible reducción del Parque Nacional Bahuaja Sonene durante el segundo gobierno del presidente García para permitir su apertura para la negociación de operaciones de hidrocarburos. El tema ha sido aparentemente descartado. 
actividad o el recurso esté bajo la competencia directa de otro sector de gobierno, como en el caso de los recursos pesqueros, los hidrocarburos o los minerales, por ejemplo. En estos casos, corresponde siempre a la autoridad de áreas protegidas dar el visto bueno u opinión favorable de manera previa al permiso que corresponda.

Como regla general, las seis categorías bajo objetivos de «uso directo» ${ }^{22}$ permiten el otorgamiento de derechos para uso sostenible de recursos renovables, con la excepción de la madera. Estos derechos pueden darse bajo la modalidad de permisos, licencias, acuerdos o concesiones. En el caso de las concesiones, las que están expresamente reguladas son las concesiones para aprovechamiento del paisaje con fines turísticos, y las concesiones para estaciones biológicas de investigación. También denominadas, de manera algo confusa, convenios de administración, que es la misma manera en que se denomina a la figura para encargar la administración de un área nacional a una institución pública.

En cuanto a las actividades prohibidas, el reglamento de la Ley de Áreas Naturales Protegidas establece una serie de restricciones específicas y otras de carácter general. Como principio tenemos que en las áreas de uso indirecto de recursos, es decir los parques nacionales, santuarios nacionales y santuarios históricos, se encuentra prohibido lo siguiente:

- el aprovechamiento de recursos no renovables ${ }^{23}$;

- el aprovechamiento de recursos naturales renovables, salvo en el caso de poblaciones locales asentadas previamente al establecimiento del área, y siempre y cuando sea con fines de subsistencia ${ }^{24}$

- la transformación de ecosistemas naturales ${ }^{25}$;

- actividades agrícolas y pecuarias, salvo en las zonas de uso especial y por poblaciones locales asentadas previamente al establecimiento del área ${ }^{26}$;

- construcción o habilitación de infraestructura y senderos que no sean compatibles con la zonificación ${ }^{27}$.

Por su parte, en las áreas de uso directo de recursos, es decir todas las demás categorías de nivel nacional, más las áreas de conservación regionales y las áreas de conservación privadas, se encuentra prohibido lo siguiente:

22 Reservas nacionales, reservas paisajísticas, reservas comunales, refugios de vida silvestre, cotos de caza y bosques de protección.

23 Artículo 115.2 del decreto supremo 038-2001-AG. Los artículos citados a continuación hasta la nota 31 refieren a este mismo decreto.

24 Artículo 89.2.

25 Artículo 102.

26 Artículo 104.

27 Artículos 174 y 175.

LEGISLACIÓN

Y CONCEPTOS

APLICABLES

A LAS ÁREAS

NATURALES

PROTEGIDAS EN

EL PERÚ

LEGISLATION

AND APPLICABLE

CONCEPTS TO

PROTECTED

NATURAL AREAS

IN PERU 
- actividades de aprovechamiento forestal, salvo por poblaciones locales asentadas previamente al establecimiento del área, y siempre y cuando sea con fines de subsistencia y en las zonas de uso especial ${ }^{28}$;

- la transformación de ecosistemas naturales ${ }^{29}$;

- actividades agrícolas y pecuarias, salvo en las zonas de uso especial y por poblaciones locales asentadas previamente al establecimiento del área ${ }^{30}$;

- la construcción o habilitación de infraestructura y senderos que no sean compatibles con la zonificación ${ }^{31}$;

- la caza deportiva es compatible con algunas categorías de uso directo $^{32}$.

En cuanto al aprovechamiento de hidrocarburos y minerales dentro de las áreas protegidas, debe tenerse en cuenta que el reglamento de la Ley de Áreas Naturales Protegidas estableció un procedimiento para los casos de operaciones de hidrocarburos o de minería en las áreas protegidas. De acuerdo con este procedimiento, el aprovechamiento de recursos naturales no renovables al interior de las áreas naturales protegidas se permite solo en las áreas de uso directo y cuando lo contemple su Plan Maestro aprobado, estando sujeto a las normas de protección ambiental y a las limitaciones y restricciones previstas en los objetivos de creación del área natural protegida, su zonificación y categorización, así como aquellas que establezca el SERNANP. En el caso de las zonas reservadas, si bien el SERNANP puede determinar que no sea posible realizar explotación de recursos no renovables hasta su categorización final; esto no ha sucedido así en la práctica y se ha dado el caso de otorgamiento de lotes de hidrocarburos sobre zonas reservadas. Lotes que luego, por esta razón, no pueden ser ya categorizadas como áreas de uso indirecto.

El artículo 116 del reglamento de la Ley de Áreas Naturales Protegidas ${ }^{33}$ estableció en detalle los pasos del procedimiento para que se realicen operaciones mineras o de hidrocarburos en toda o parte del área protegida o su zona de amortiguamiento. Dicho artículo fue modificado en el año $2011^{34}$, regulándose no solo el aprovechamiento de minería e hidrocarburos, sino también la habilitación de infraestructura al interior de áreas protegidas. Básicamente en estas normas se establece un procedimiento de emisión de compatibilidad y de opinión técnica previa vinculante.

32 Reservas paisajísticas, reservas nacionales, reservas comunales, bosques de protección y cotos de caza. 


\section{GESTIÓN INSTITUCIONAL DE LAS ÁREAS NATURALES PROTEGIDAS}

La autoridad de las áreas naturales protegidas corresponde al Servicio Nacional de Áreas Naturales Protegidas (SERNANP), organismo técnico especializado bajo la estructura del Ministerio del Ambiente. Tanto el Ministerio como el SERNANP son instituciones relativamente nuevas, creadas en mayo de 2008 y que prácticamente completaron la asignación de sus competencias durante la primera mitad del año 2009. Anteriormente a estas instituciones, las áreas naturales protegidas estuvieron siempre bajo alguna dependencia del Ministerio de Agricultura. Entre 1992 y el año 2008, bajo el Instituto Nacional de Recursos Naturales (INRENA).

De acuerdo con la norma de creación del Ministerio del Ambiente y sus modificatorias, son funciones del SERNANP las siguientes:

a) Dirigir el Sistema Nacional de Áreas Naturales Protegidas por el Estado (SINANPE) y asegurar su funcionamiento como sistema unitario.

b) Aprobar las normas y establecer los criterios técnicos y administrativos, así como los procedimientos para el establecimiento y gestión de las áreas naturales protegidas.

c) Orientar y apoyar la gestión de las áreas naturales protegidas cuya administración está a cargo de los gobiernos regionales y locales y los propietarios de predios reconocidos como áreas de conservación privada.

d) Establecer los mecanismos de fiscalización y control y las infracciones y sanciones administrativas correspondientes; y ejercer la potestad sancionadora en los casos de incumplimiento, aplicando las sanciones de amonestación, multa, comiso, inmovilización, clausura o suspensión, de acuerdo al procedimiento que se apruebe para tal efecto.

e) Asegurar la coordinación interinstitucional entre las entidades del gobierno nacional, los gobiernos regionales y los gobiernos locales que actúan, intervienen o participan, directa o indirectamente, en la gestión de las áreas naturales protegidas.

f) Emitir opinión previa vinculante a la autorización de actividades orientadas al aprovechamiento de recursos naturales o a la habilitación de infraestructura en el caso de las áreas naturales protegidas de administración nacional.

g) Emitir opinión sobre los proyectos normativos referidos a instrumentos de gestión ambiental, considerando las necesidades y objetivos de las áreas naturales protegidas ${ }^{35}$.

LEGISLACIÓN

Y CONCEPTOS

APLICABLES

A LAS ÁREAS

NATURALES

PROTEGIDAS EN

EL PERÚ

LEGISLATION

AND APPLICABLE

CONCEPTS TO

PROTECTED

NATURAL AREAS

IN PERU 
Administrar el patrimonio forestal, flora y fauna silvestre de las áreas naturales protegidas y sus servicios ambientales ${ }^{36}$.

A nivel de las áreas existe una estructura encabezada por un jefe para cada área natural protegida, quien cuenta además con profesionales especializados y guardaparques. Un órgano importante de apoyo para la gestión de cada área natural protegida está dado por los Comités de Gestión. Estos son espacios que reúnen a representantes de cualquier grupo de interés sean públicos, privados o comunales.

\section{Cuadro 2. Principales hitos de la evolución institucional de las áreas naturales protegidas en el Perú}

1963 Servicio forestal y de caza, dentro del Ministerio de Agricultura.

1969 Dirección General Forestal, de caza y tierras, dentro del Ministerio de Agricultura y Pesquería.

1972 Dirección General de Forestal y Caza.

1977 Dirección General Forestal y de Fauna, que cuenta con una Dirección de Conservación, que a su vez tiene una Sub-Dirección de Parques Nacionales, a cargo de las ANP.

1981 Se crea el Instituto Nacional Forestal y de Fauna (INFOR); que absorbe a la Dirección de Conservación de la Dirección General Forestal y de Fauna. Dentro del INFOR se establece una Dirección de Parques Nacionales (1981-1987).

1987 Dirección de Parques Nacionales regresa a Dirección General Forestal y de Fauna (DGFF).

1990 Programa «Parques Nacionales Perú» (PNP). Organismo descentralizado de la DGFF. DGFF mantiene competencias normativas y de supervisión. PNP asume competencias de gestión de las áreas.

1992 - Instituto Nacional de Recursos Naturales (INRENA) y Dirección General de ANP y Fauna Silvestre.

- Fondo Nacional de las Áreas Naturales Protegidas (FONANPE). Su ente administrador se denomina (PROFONANPE).

2001 Sale Fauna Silvestre del ámbito de la Dirección General de Áreas Naturales Protegidas.

2003 Intendencia de Áreas Naturales Protegidas, siempre dentro del INRENA.

2008 Ministerio del Ambiente y Servicio Nacional de Áreas Naturales Protegidas como organismo técnico especializado del Ministerio del Ambiente. 
VII. IMPLEMENTACIÓN DE LAS NORMAS Y PENALIDADES El jefe del área y los guardaparques a su cargo tienen facultades para inmovilizar productos ilegales (pieles, madera, etcétera) ${ }^{37}$. Inmediatamente a esto deben levantar un acta y llamar a la policía, quienes tienen las competencias directas para detener infractores y movilizar productos decomisados.

Lamentablemente, el personal de las ANP es aún escaso y las áreas protegidas se ubican en zonas remotas con muy poca presencia del Estado, lo que hace que las coordinaciones entre el personal del área y la policía sea muy difícil. Ante esto, las posibilidades efectivas de atacar las infracciones dentro de las áreas protegidas son muy bajas; y solo hay muestras de éxito en aquellos casos de áreas más vinculadas a entornos urbanos o en áreas donde se realizan operativos especiales por denuncias graves o situaciones reiteradas. Estos operativos son normalmente costosos y pocas veces el Sistema puede destinar un presupuesto específico para este fin $^{38}$. El problema del cumplimiento de las normas sobre áreas protegidas está entonces muy condicionado por una institucionalidad que, aún cuando ha mejorado significativamente, sigue siendo débil a nivel político, estructural y financiero; y, por lo tanto, es muy difícil que logre implementar sus mandatos y responsabilidades.

\section{Penalidades}

En el año 2005, la Ley General del Ambiente precisó que corresponde a la autoridad nacional de ANP ejercer la potestad sancionadora, aplicando las sanciones de amonestación, comiso, clausura o suspensión, por las infracciones que sean determinadas por Decreto Supremo y de acuerdo al procedimiento que se apruebe para tal efecto ${ }^{39}$. Así, en el año 2010 se publicó el decreto supremo 019-2010-MINAM, mediante el cual se reglamenta el procedimiento administrativo sancionador por afectación a las ANP, en esta norma se consideran los siguientes tipos de sanciones:

[...] c) Amonestación: Es una sanción que se materializa con una llamada de atención escrita al infractor, instándolo a no incurrir en nuevas contravenciones. $[\ldots]$

i) Clausura: Sanción no pecuniaria que consiste en la prohibición de funcionamiento temporal o definitivo de establecimientos donde se lleven a cabo actividades prohibidas legalmente o que constituyan peligro o riesgo para las especies forestales, de fauna o flora silvestre.

37 Artículos 24.3, literal n, y 27.1, literal I, del decreto supremo 038-2001-AG.

38 En enero del año 2009, un operativo destinado a desalojar invasores del Santuario Histórico de Pómac tuvo un trágico desenlace con la muerte de dos policías. Entre otras cosas, se cuestionó mucho el presupuesto asignado al operativo, donde no había alimentos suficientes ni equipos para que los policías cumplan su función.

39 Primera Disposición Complementaria de la ley 28.611.

LEGISLACIÓN Y CONCEPTOS APLICABLES A LAS ÁREAS NATURALES PROTEGIDAS EN EL PERÚ

LEGISLATION AND APPLICABLE CONCEPTS TO PROTECTED NATURAL AREAS IN PERU 
Puede aplicarse además por incumplimiento de las obligaciones asumidas al momento de otorgarse los permisos, las licencias o autorizaciones.

La clausura puede ser temporal o definitiva, aplicándose esta última en los supuestos de reincidencia y/o por la gravedad de la infracción cometida.

$[\ldots]$

k) Comiso: Es una sanción no pecuniaria accesoria que puede ser temporal como definitiva, como consecuencia de una infracción tipificada en el presente Reglamento que conlleva la privación de los semovientes, vehículos terrestres, acuáticos o aéreos, artefactos, objetos, instrumentos, herramientas, maquinaria, sustancias y/o embarcaciones, con que se hubiere ejecutado, así sean o no de los infractores.

$[\ldots]$

r) Multa: Es una sanción de carácter pecuniario establecida de acuerdo a la gravedad de la infracción y determinada sobre la base de la unidad impositiva Tributaria (U.I.T.).

$[\ldots]$

u) Suspensión del permiso, licencia, concesión o cualquier otra autorización: Es la privación temporal de los efectos jurídicos propios de un acto administrativo (permiso, licencia, concesión o autorización u otros análogos) por el incumplimiento de sus obligaciones ${ }^{40}$.

En cuanto al comiso, que es una de las penalidades más frecuentes dentro de las ANP, el reglamento señala que una vez detectada la infracción por el personal del área se procede a levantar un Acta Probatoria, en el lugar de la intervención, en la que se debe dejar constancia de lo siguiente:

a) la identificación del sujeto intervenido y, en su caso, del infractor;

b) la infracción cometida;

c) identificación y descripción del bien o los bienes materia de comiso, precisando su estado de conservación y el número de los mismos;

d) lugar y fecha de la intervención; y,

e) la firma del sujeto intervenido, la constancia de la negativa de recepción o de la negativa a la firma, o, la imposibilidad de identificar al infractor ${ }^{41}$. 
El reglamento establece también agravantes, los cuales están constituidos por cuestiones de «reincidencia, y la caza, captura, colecta, transformación con fines de comercio de ejemplares de especies de fauna y flora silvestre» ${ }^{42}$ en situación de peligro. En estos casos, se puede elevar el monto de la sanción de multa hasta el triple del límite máximo establecido.

Asimismo, el SERNANP, mediante el decreto legislativo 1079 y su reglamento ${ }^{43}$, norma la recuperación de los especímenes, productos y subproductos de fauna y flora silvestre. El personal del SERNANP debidamente acreditado para ejercer esta facultad procederá a recuperar algún espécimen, producto o subproducto de flora y fauna silvestre, si es que alguna persona se encuentra en posesión de ellos sin ningún tipo de permiso o autorización. Cabe resaltar que la recuperación no es igual a un comiso ni forma parte del procedimiento sancionador ${ }^{44}$.

En octubre del año 2008 se establecieron modificaciones al Código Penal donde se establecen como agravantes con penas privativas de la libertad de entre cuatro y siete años, a los delitos cometidos dentro de áreas naturales protegidas, referidos a:

- tráfico ilegal de especies acuáticas de flora y fauna;

- extracción ilegal de especies acuáticas;

- depredación de flora y fauna silvestre protegida;

- tráfico ilegal de recursos genéticos;

- delitos contra los bosques o formaciones boscosas;

- tráfico ilegal de productos forestales maderables;

- obstrucción del procedimiento ${ }^{45}$.

Estas nuevas penalidades rigen desde enero de 2009.

\section{DERECHOS DEPROPIEDAD YOTROS DERECHOS PREEXISTENTES AL ESTABLECIMIENTO DEL ÁREA NATURAL PROTEGIDA}

Si bien se espera que las áreas protegidas sean establecidas sobre terrenos públicos, es posible que las áreas protegidas se establezcan incluyendo uno o más predios sobre los que hay derechos preexistentes, sean de propiedad, posesión, concesión o simplemente certificados de uso. En la mayoría de los casos, los titulares de estos derechos son campesinos, ganaderos, indígenas y colonos o concesionarios sobre el uso de recursos 
naturales. De acuerdo a la legislación de áreas naturales protegidas, los derechos preexistentes al establecimiento de un área natural protegida se respetan y, en la medida de lo posible, se mantienen las prerrogativas de uso del propietario ${ }^{46}$. Este es un punto poco trabajado, sin embargo, en el Perú. En la práctica se ha cometido muchos abusos derivados de la falta de una política clara sobre el tema y donde un esquema de compensaciones o asistencia a propietarios u otros titulares de derechos ha estado totalmente ausente.

Hasta la fecha tampoco se ha hecho ninguna expropiación para establecer áreas protegidas; que es una prerrogativa siempre disponible por causas de interés público, donde evidentemente el establecimiento de un área natural protegida lo justifica. La costumbre es que simplemente se establecen las ANP superponiéndose a zonas que muchas veces tienen derechos anteriores, y los propietarios no reciben información suficiente sobre las limitaciones a sus derechos de uso. Dependiendo de cada caso, algunas veces estas limitaciones son impuestas sin compensación alguna o, por el contrario, se aceptan los usos que viene dando el propietario, aun cuando puedan contraponerse a los objetivos de manejo del área.

La ley de áreas protegidas y su reglamento tienen un mecanismo interesante sobre transferencia de propiedad al interior de las áreas protegidas. El reglamento establece que:

[...] en caso de venta de predios privados al interior de un área natural protegida, el propietario deberá otorgar una primera opción de compra al Estado, mediante carta notarial a la Jefatura del Área, por un plazo no menor a sesenta (60) días. En caso que el Estado no ejerza la opción de compra, siempre le corresponderá el derecho de retracto, de acuerdo al Artículo 5을 de la Ley № 26834 ${ }^{47}$.

La opción de compra se refiere a la obligación de cualquier propietario de ofrecer primero al Estado la opción de comprar el predio. En caso el Estado no tome esta opción, el propietario podrá vender su propiedad a un tercero, pero aun en este caso el Estado puede ejercer su derecho de retracto. Es decir, el Estado puede subrogarse en el lugar del comprador, reembolsando a este el precio pagado, dentro de los treinta días siguientes a que reciba la comunicación de la compra-venta. 


\section{CO-MANEJO O MANEJO DELEGADO DE ÁREAS PROTEGIDAS POR INSTITUCIONES DE DERECHO PRIVADO}

Este es un tema que ya ha empezado a implementarse en el Perú a dos niveles: mediante la firma de contratos de administración con organizaciones sin fines de lucro; y mediante el mismo mecanismo, pero con reglas especiales para el caso de comunidades indígenas en las reservas comunales. En ambos casos la figura legal se llama contrato de administración. El concepto es que la autoridad de áreas protegidas a nivel central puede encargar, a una institución sin fines de lucro de la sociedad civil, el gerenciamiento de un área protegida bajo un modelo de contrato de gestión por resultados. Si bien en un principio hubo alguna resistencia a implementar este instrumento por ser mal interpretado por algunos como una manera asolapada de «privatizar» las áreas protegidas, ha empezado a desarrollarse con mucha fuerza en los últimos años y a la fecha ya hay más de diez áreas protegidas bajo contratos de administración. Los titulares de estos contratos son, en casi todos los casos, organismos no gubernamentales $(\mathrm{ONG})$ de conservación o desarrollo, y existe un caso donde el titular es un club de caza y pesca que administra un coto de caza.

En el caso de las reservas comunales, estas poseen un régimen legal especial.Las reservas comunales sonáreas protegidas de aprovechamiento de recursos establecidas en beneficio de una población específica, y que en la práctica está muy asociado a áreas de manejo indígena. En estas áreas, el titular del contrato de administración es siempre la población beneficiaria de la reserva comunal, población que debe elegir a sus representantes y constituir una persona jurídica que asuma la titularidad del contrato de administración.

\section{RETOS HACIA EL FUTURO}

Si bien los avances en el Sistema peruano de Áreas Naturales Protegidas han sido significativos, aún quedan muchos retos pendientes. Los más importantes desde lo legal e institucional podríamos resumirlos en los siguientes puntos:

- Consolidar el recientemente creado Servicio Nacional de Áreas Naturales Protegidas (SERNANP). Hay todavía algunos procedimientos y competencias por definir, la mayoría referidos a las competencias y funciones de SERNANP versus funciones y competencias de otros sectores y niveles de gobierno como pesquería, minería, hidrocarburos, etcétera.

- Consolidar los niveles subnacionales de áreas naturales protegidas. Las áreas protegidas municipales no son legalmente «áreas protegidas», pero curiosamente son frecuentemente

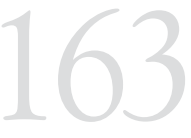

LEGISLACIÓN

Y CONCEPTOS

APLICABLES

A LAS ÁREAS

NATURALES

PROTEGIDAS EN

EL PERÚ

LEGISLATION

AND APPLICABLE

CONCEPTS TO

PROTECTED

NATURAL AREAS

IN PERU 
utilizadas por las autoridades municipales como estrategias de conservación local. Las áreas protegidas departamentales, denominadas «áreas de conservación regional», han empezado a desarrollarse aunque aún hay varios puntos que requieren ser definidos legal e institucionalmente. La interacción entre el sistema nacional y los emergentes sistemas regionales es algo que deberá también trabajarse en los próximos años.

- Consolidar y simplificar algunos instrumentos de gestión, como los planes maestros, para que resulten más eficientes hacia un enfoque efectivo de gestión de las áreas, y que permitan condiciones más favorables para el uso público y la gestión sostenible de recursos en las áreas aptas para ello.

- Adecuar la legislación vigente a los nuevos conceptos y tendencias. Las menciones a cambio climático o a modelos de pago por servicios ambientales son prácticamente inexistentes en la legislación vigente de áreas protegidas, así como conceptos en desarrollo como la «adaptación basada en ecosistemas».

- Algunas definiciones de categorías de áreas requieren ser también revisadas, así como resultaría interesante discutir la incorporación de nuevas estrategias y categorías que ya son utilizadas en otros países.

- Cubrir la brecha financiera para el adecuado manejo de las áreas protegidas. El presupuesto asignado por tesoro público es aún muy bajo comparado con las necesidades y retos de las áreas, de modo que las opciones para implementar realmente los planes maestros y hacer un manjeo adecuado de las mismas son muy escasas. El presupuesto actual de las áreas permite mayormente atender actividades de control y aun para esto falta personal y equipo. La investigación, la promoción y puesta en valor de las áreas para su uso público u otras actividades son bastante relegadas o dependientes de ser implementadas por terceros.

- Desarrollar mejores principios y metodologías en la relación con las comunidades indígenas y poblaciones locales. Guías y protocolos para la suscripción de acuerdos con pobladores que viven dentro de las áreas o en sus zonas de amortiguamiento serían muy útiles para enfrentar este tema. 